\title{
Association between Sleep Duration, Use of Electronic Devices and Obesity in Medical Students
}

\author{
Tapaswini Mishra ${ }^{1}$, Manika Bose ${ }^{2}$, Prajyoti Behera ${ }^{1}$, Dipti Mohapatra ${ }^{1, *}$, Arati Meher ${ }^{1}$, \\ Priyambada Panda ${ }^{1}$, Mitu Mohanty ${ }^{3}$ \\ ${ }^{1}$ Department of Physiology, IMS and SUM Hospital, Siksha 'O' Anusandhan University, Bhubaneswar, India \\ ${ }^{2}$ Department of Pharmacology, IMS and SUM Hospital, Siksha 'O' Anusandhan University, Bhubaneswar, India \\ ${ }^{3}$ Consultant Pathologist, Nigam Health Clinic, Bhubaneswar, India
}

Received October 4, 2021; Revised December 2, 2021; Accepted December 12, 2021

\section{Cite This Paper in the following Citation Styles}

(a): [1] Tapaswini Mishra, Manika Bose, Prajyoti Behera, Dipti Mohapatra, Arati Meher, Priyambada Panda, Mitu Mohanty, "Association between Sleep Duration, Use of Electronic Devices and Obesity in Medical Students," Universal Journal of Public Health, Vol. 9, No. 6, pp. 454 - 459, 2021. DOI: 10.13189/ujph.2021.090613.

(b): Tapaswini Mishra, Manika Bose, Prajyoti Behera, Dipti Mohapatra, Arati Meher, Priyambada Panda, Mitu Mohanty (2021). Association between Sleep Duration, Use of Electronic Devices and Obesity in Medical Students. Universal Journal of Public Health, 9(6), 454 - 459. DOI: 10.13189/ujph.2021.090613.

Copyright $\odot 2021$ by authors, all rights reserved. Authors agree that this article remains permanently open access under the terms of the Creative Commons Attribution License 4.0 International License

\begin{abstract}
Background: With the advancement in technology and use of multiple electronic devices and decreasing duration of sleep, adolescents are more prone to obesity, i.e., increased BMI (body mass index). Objectives: The objectives of the study were to determine the association between sleep duration, use of electronic devices, and obesity in medical students. Methods: Medical students between the age groups 17-22 years were recruited. The study design was cross-sectional. The main study variables were the type and duration of use of various electronic devices during daytime and bedtime. The independent variable used in the study was the subjects' self-reported average number of hours of sleep obtained per night based on the questionnaire. To calculate the BMI, height and weight were obtained. Results: There is a significant association between short sleep duration and prolonged use of electronic devices. $(p<0.01)$ Those who engaged in electronic devices for a longer period had significantly higher BMI (obesity) $\mathrm{p}<$ 0.001. Maximum use of mobile phones was found during bedtime. The males were using more mobile phones for video gaming than female medical students. Conclusions: Reducing bedtime use of electronic devices and improving sleep hygiene in adolescents could decrease the prevalence of obesity in adolescents.
\end{abstract}

Keywords Sleep Duration, Electronic Devices,
Obesity, Medical Students

\section{Introduction}

The prevalence of obesity is increasing day by day in recent time, one of the main health problems worldwide. Modern technologies and the use of several electronic devices may be associated with an increase in body mass index (BMI). There is a relationship between sleep and obesity in adolescents particularly in medical students where their sleep cycle is altered [1,2].

In the last ten to twenty years, there is a sharp increase in the availability and use of electronic gadgets like mobile phones, video gaming devices, television, laptops, computers, tablets, I- pads, etc. So, this has become a very important part of adolescent lives, which has been found that about $97 \%$ of American adolescents have at least one electronic device in the bedroom. Not only do electronic devices play an important role for entertainment purposes in adolescents but also play a major role in social lives. By using various electronic devices regularly and for more periods will affect sleep which hurts adolescents' life [3]. Increased use of multiple electronic devices has been shifted to sleep deficiency among adolescents in the 
last decade.[4] Recent studies show that the use of electronic devices leads to late bedtime sleep and there is approximately daily sleep deficiency of about two hours [5].

The use of multiple electronic devices is highly seen in adolescents nowadays which is associated with obesity, but bedtime use is not explored in a lot of research studies. It has been seen that decreased sleep duration is associated with obesity in adolescents [6].

The mechanism with the correlation between the use of various electronic devices and sleep duration has not been known exactly, but maybe due to the time-consuming nature of electronic devices which leads to poorer sleep or an increase in arousal time because of exposure to bright light from the electronic devices [7].

Bright light causes a delay in circadian rhythm when used at bedtime [8] and increases alertness of the brain $[9,10]$. Exposure to electromagnetic radiation from the electronic devices is sensed by the pineal gland as light so, it decreases melatonin secretion and decreases sleep duration. Therefore, sleep is indirectly proportional to electromagnetic radiation [7]. The other cause by which there is sleep impairment is physical discomfort such as musculoskeletal pain and headache because of the prolonged use of electronic devices (like mobile phones and computer games) [11]. Using the electronic devices constantly in the bed before sleep decreases the inducing properties which causes sleep [12].

There is a sharp increase in the prevalence of obesity in the past ten to twenty years which has caused obesity to be a major global public health concern. There is the early development of obesity complications because of the increase in the prevalence of obesity in childhood and adolescence which results in continued obesity in adulthood [1,2]. Adolescence is the important period with increasing vulnerability to obesity [13]. By frequent use of television, smartphones, tablets, videogames, laptops, computers, etc. at the time of adolescence period which has been associated with obesity later [14].

A decrease in sleep duration has an important role in the development of obesity. As sleep loss causes hormonal imbalance in the body that causes overeating and gaining more weight. The hormones that regulate appetite are leptin and ghrelin and there is insufficiency of sleep the production of these hormones is altered which increases the feeling of hunger.

The objectives of the study were to determine the association between sleep duration, use of electronic devices, and obesity.

The present study discusses the association between sleep, use of electronic devices, and obesity in medical students.

\section{Materials and Methods}

The study was carried out in the Physiology
Department, Institute of Medical Sciences, and SUM Hospital, Bhubaneswar. The study design was a cross-sectional study. The inclusion criteria were the first-year medical students between the age groups 17-22 years. The study was questionnaire-based. The height and weight of the students were obtained to calculate the BMI. The variable which was independent in the study was by the students who reported self the average number of hours they slept per night. The question asked was, "How many hours of sleep do you usually get a night (or when you usually sleep)?" The students were asked if they had any trouble waking up during the night and also if they were feeling excessive sleepiness during the daytime. Exclusion criteria were the students who are diagnosed with disorders of sleep, either they were taking any medication for sleep or had recently traveled to a different time zone four weeks before the data collection time.

The electronic devices which were taken for the study were the use of television, laptop/PC, mobile phones, tablet/I pad, and MP3 player during the time of bed and day. The duration of various electronic devices is then calculated which is used on days of the week at bedtime and daytime.

Statistical analysis was done by using SPSS software.

\section{Results}

100 medical students were taken for the study who have given written consent to participate in the study, out of which 43 students were males and 57 students were females.

Table 1. Association between duration of sleep and use of electronic devices

\begin{tabular}{|c|c|c|c|}
\hline Duration in hrs & \multicolumn{3}{|c|}{ Duration of Sleep in 24 hrs } \\
\hline & $<5 \mathrm{hrs}$ & $6 \mathrm{hrs}$ & $>7 \mathrm{hrs}$ \\
\hline $\begin{array}{c}\text { Duration of use } \\
\text { of the electronic } \\
\text { device }\end{array}$ & $\geq 3 \mathrm{hrs}$ & $\geq 1 \mathrm{hrs} \leq 3 \mathrm{hrs}$ & $\leq 1 \mathrm{hrs}$ \\
\hline
\end{tabular}

Table 1 shows that the association between short sleep duration and prolonged use of electronic devices is highly significant with $\mathrm{p}<0.01$

Table 2. Association between use of electronic devices and obesity

\begin{tabular}{|c|c|c|c|}
\hline Variables & \multicolumn{3}{|c|}{ Duration of use of electronic devices } \\
\hline & $\leq 1 \mathrm{hrs}$ & $>1 \mathrm{hrs}$ to $\leq 3 \mathrm{hrs}$ & $>3 \mathrm{hrs}$ \\
\hline $\begin{array}{c}\text { N(no. of } \\
\text { students) }\end{array}$ & 63 & 34 & 3 \\
\hline Mean BMI & 22.24 & 28.18 & 37 \\
\hline SD & 3.14 & 5.99 & 2.69 \\
\hline
\end{tabular}

Table 2 shows that the association between the use of various electronic devices for a longer period and high BMI (obesity) is highly significant with $\mathrm{p}<0.001$. 
Table 3. Average duration of use of electronic devices at bedtime and daytime

\begin{tabular}{|c|c|c|}
\hline Electronic devices & $\begin{array}{c}\text { Average duration } \\
\text { at bedtime }\end{array}$ & $\begin{array}{c}\text { Average duration } \\
\text { at daytime }\end{array}$ \\
\hline Mobile phone & $2.35 \mathrm{hrs}$ & $1.55 \mathrm{hrs}$ \\
\hline Television & $0.50 \mathrm{hrs}$ & $0.16 \mathrm{hrs}$ \\
\hline Tablet/iPad & $1.2 \mathrm{hrs}$ & $0.46 \mathrm{hrs}$ \\
\hline Laptop/PC & $1.3 \mathrm{hrs}$ & $0.52 \mathrm{hrs}$ \\
\hline MP3 player & $0.45 \mathrm{hrs}$ & $0.53 \mathrm{hrs}$ \\
\hline
\end{tabular}

Table 3 shows the maximum use of mobile phones during bedtime and the minimum use of television during the daytime.

Figure 1 shows that the males use more mobile phones, tablets/ iPads than female students whereas the females use more laptops, television, and MP3 than male students. $92 \%$ of the male students used mobile phones and $86 \%$ of female students used mobile phones, $35 \%$ of males and $52 \%$ of females watched television, $86 \%$ of males and $66 \%$ of females used tablet/ I pad, $85 \%$ of males and $92 \%$ of females used laptop/PC and $42 \%$ of males and $62 \%$ of females listen to MP3.

\section{Discussion}

The present study shows that the association between short sleep duration and prolonged use of electronic devices is highly significant. According to Mari Hysing et al. [15], there is an association between electronic media use and short sleep duration including SOL, which was by the findings of the authors [16, 17].

The present study shows that the association between the use of various electronic devices for a longer period and high BMI i.e., obesity is highly significant. This is in accordance with Mari Hysing et al. [15] There have been several studies that show an association between the use of various electronic devices and obesity recently [6]. Previously obesity has been related to withdrawal from society [18]. Using various electronic devices could enhance sedentary life as well as decrease active behaviors which may cause energy imbalance. The use of electronic devices is associated with an increase in food consumption without hunger which results in an increase in food consumption in adolescents [19]. Nowadays, adolescents eat a lot of junk food like fast food and beverages and use various electronic devices increases the consumption of these food and beverages [20].

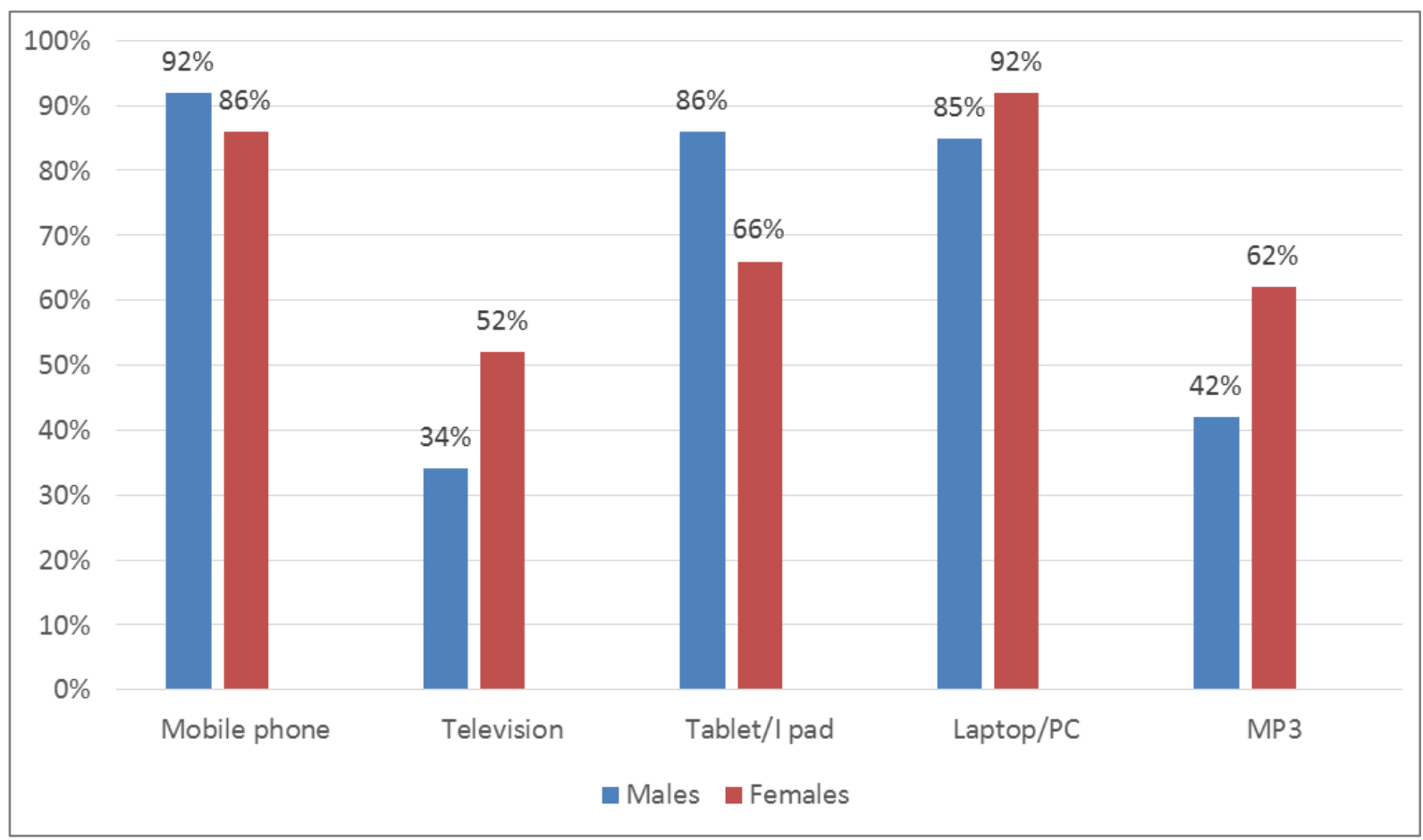

Figure 1. Use of electronic devices among male and female students 
Some studies show that there are significant independent associations between obesity and the use of various electronic devices like television, laptops, computer, video gaming devices [21-23]. There are also significant studies related to using television, computer, and video games with obesity but fewer studies between the use of smartphones, tablets, iPads, and obesity. According to T. Arora et al. (2013), there is no relationship between weekday mobile use and obesity because smartphones, tablets, and iPads are portable and they don't require the fixed position of the body to use, instead, they result in increased movement and energy expenditure compared to television, internet, and computer. Future studies may investigate in more detail the use of mobile phones, tablets, iPads other than watching television, using computers, and the internet. According to Taheri et al. short duration of sleep may lead to obesity because of hormonal imbalance between leptin and ghrelin which causes more food intake [24]. Short sleep duration causes an increase in hunger and appetite and craving for unhealthy junk food because of alteration of metabolic hormones. Some recent studies also show that imbalance hormone metabolism is due to misalignment of the circadian rhythm. So, there are several heterogeneous findings between metabolic hormones alteration or energy balance and sleep duration in adolescents [25-27].

The present study shows that the average duration of use of smartphones at bedtime is maximum and minimum use of television in the daytime because of newer technologies of gaming in the smartphone. Although the number of times the use of electronic devices differed there was a significant association between the use of different electronic devices and sleep. Other studies show that there is a significant relationship between television and sleep [28,29], which can be generalized to newer technologies. Some studies also show the relationship between laptop/PC and poorer sleep [30] and decreased bedtime. $[16,17]$. The use of different electronic devices such as computers, mobile smartphones, television, and video gaming devices before bedtime were all associated with an increase in sleep deficit. So, if the adolescent uses electronic devices, the total for more than 4 hours after school was prone to sleep deficit. When the study was conducted separately for different electronic devices at all times if the daytime screen uses more than 2 hours then it was significantly associated with sleep deficit [15].

There are many causes to explain the relationship between the duration of sleep and the use of electronic devices. The utilization of electronic devices affects sleep by consuming more time and interfering with sleep by increased psychological and physiological awakening. Because of the exposure of bright light from electronic devices, it interferes with sleep by delaying the circadian rhythm $[7,8]$.

The present study shows that male students use more mobile phones, tablets/ iPads than female students this is because they play various games on these devices, whereas female students use more laptops, television, and MP3 than male students, but according to Mari Hysing et al. [15] boys spend more time on console games, PC games whereas girls were more involved in online chat and other PC use. In our study as well as according to Mari Hysing et al. [15] the electronic devices were more used before bedtime. In this study, it was found that boys used more time on mobile phones and tablets/ I pad to play video games whereas girls used more time on mobile phones and listening to music by Mp3 players $(\mathrm{p}<0.001)$. Girls were significantly more involved in online chatting and computer use whereas boys were more involved in video gaming devices and computer games $(\mathrm{p}<0.001)$.

The present study shows that there is an association between prolonged use of different electronic devices and sleep deficiency $(\mathrm{p}<0.01)$, and other studies also show a powerful relation between the use of electronic devices and sleep deficiency because of using more electronic devices and less sleeping hours [31].

\section{Summary and Conclusion}

Although the importance of different electronic devices is still to be discussed, it is found that the electronic devices used for social communication have a negative effect on sleep. Some studies show that there are statistically significant differences between the various electronic devices. Because there are numerous functions and tasks of different electronic devices, so the association between sleep and electronic devices should be studied thoroughly [2].

The present study will have a great impact on public health if the use of electronic devices is not decreased. Constant advances in technologies of electronic devices, easy availability, and accessibility will promote more use of devices, decreasing physical activity which will accelerate the current obesity epidemic. Therefore, this study shows that using mobile phones for a prolonged period at bedtime is a major public health issue like skin cancer due to radiation, neck problems, psychological issue, sleep deprivation, etc. [32] in adolescents and it should be prevented. Parents should be involved and should set the bedtime for adolescents to maintain good sleep hygiene and to decrease the prevalence of obesity in adolescents.

\section{REFERENCES}

[1] Wang Y, Lobstein T, "Worldwide trends in childhood overweight and obesity", International Journal of Pediatric Obesity, vol. 1, no.1, pp. 11-25, 2006. DOI: 10.1080/17477160600586747

[2] Clarke WR, Lauer RM, "Does childhood obesity track into 
adulthood?", Critical Reviews in Food Science and Nutrition. vol. 33, no.4-5, pp. 423- 430, 1993. DOI: $10.1080 / 10408399309527641$

[3] Van den Bulck J., "Text messaging as a cause of sleep interruption in adolescents, evidence from a cross-sectional study", Journal of Sleep Research, vol. 12, no.3. pp. 263. 2003. DOI: 10.1046/j.1365-2869.2003. 00362.x

[4] Pallesen S, Hetland J, Sivertsen B, Samdal O, Torsheim T, Nordhus IH, "Time trends in sleep-onset difficulties among Norwegian adolescents: 1983-2005", Scandinavian Journal of Public Health, vol. 36, no.8. pp. 889-895. 2008. DOI: $10.1177 / 1403494808095953$

[5] Hysing M, Pallesen S, Stormark KM, Lundervold AJ, Sivertsen B, "Sleep patterns and insomnia among adolescents: a population-based study", Journal of Sleep Research, vol.22, no. 5, pp. 549-556, 2013. DOI: $10.1111 /$ jsr. 12055

[6] Arora T, Hosseini-Araghi M, Bishop J, Yao G.L, Thomas G.N and Taheri S. "The complexity of obesity in UK adolescents: relationships with quantity and type of technology, sleep duration and quality, academic performance and aspiration", Pediatric Obesity. vol. 8, no. 5, pp. 358-366, 2013. DOI: 10.1111/j.2047-6310.2012. 00119.x

[7] Cain N, Gradisar M, "Electronic media use and sleep in school-aged children and adolescents: A review", Sleep Medicine, vol. 11, no. 8, pp. 735-742, 2010. DOI: 10.1016/j.sleep.2010.02.006

[8] Khalsa SB, Jewett ME, Cajochen C, Czeisler CA, "A phase response curve to single bright light pulses in human subjects", The Journal of Physiology, vol.549, no. 3, pp.945-952, 2003. DOI: 10.1113/jphysiol.2003.040477

[9] Weaver E, Gradisar M, Dohnt H, Lovato N, Douglas P, "The effect of presleep video-game playing on adolescent sleep", Journal of Clinical Sleep Medicine, vol.6, no. 2, pp. 184-189, 2010. PMID: 20411697; PMCID: PMC2854707.

[10] Campbell SS, Dijk DJ, Boulos Z, Eastman CI, Lewy AJ, Terman M, "Light treatment for sleep disorders: consensus report. III. Alerting and activating effects", Journal of Biological Rhythms, vol.10, no. 2, pp. 129-132, 1995, DOI: $10.1177 / 074873049501000205$.

[11] Thomee S, Dellve L, Harenstam A, Hagberg M, "Perceived connections between information and communication technology use and mental symptoms among young adults - a qualitative study", BMC Public Health, vol. 10, no.1, pp. 66, 2010, DOI: 10.1186/1471-2458-10-66.

[12] Hauri P, Fisher J," Persistent psychophysiologic (learned) insomnia", Sleep, vol.9, no.1, pp. 38-53, 1986, DOI: 10.1093/sleep/9.1.38.

[13] Alberga AS, Sigal RJ, Goldfield G, Prud'homme D, Kenny GP, "Overweight and obese teenagers: why is adolescence a critical period?", Pediatric Obesity, vol.7, no.4, pp. 261-273, 2012, DOI: 10.1111/j.2047-6310.2011.00046. x.

[14] Parsons TJ, Manor O, Power C, "Television viewing and obesity: a prospective study in the 1958 British birth cohort", European Journal of Clinical Nutrition, vol.62, no. 12, pp. 1355-1363, 2008, DOI: 10.1038/sj.ejcn.1602884.
[15] Hysing M, Pallesen S, Stormark KM, Jakobsen R, Lundervold AJ, Sivertsen B, "Sleep and use of electronic devices in adolescence: results from a large population-based study", BMJ Open, vol. 5, no.1, pp. e006748, 2015, DOI: 10.1136/BMJ open-2014-006748.

[16] Punamäki RL, Wallenius $M$, Nygård $\mathrm{CH}$, Saarni L, Rimpelä A, "Use of information and communication technology (ICT) and perceived health in adolescence: the role of sleeping habits and waking-time tiredness", Journal of Adolescence, vol.30, no.4, pp. 569-585, 2007, DOI: 10.1016/j.adolescence.2006.07.004

[17] Yen CF, Ko CH, Yen JY, Cheng CP, "The multidimensional correlates associated with short nocturnal sleep duration and subjective insomnia among Taiwanese adolescents", Sleep, vol. 31, no.11, pp.1515-1525, 2008, DOI: 10.1093/sleep/31.11.1515.

[18] Griffiths LJ, Page AS, "The impact of weight-related victimization on peer relationships: the female adolescent perspective”, Obesity (Silver Spring), vol.16, no. Suppl 2, pp. S39-45, 2008, DOI: 10.1038/oby.2008.449.

[19] Chaput JP, Visby T, Nyby S, Klingenberg L, Gregersen NT, Tremblay A, Astrup A, Sjödin A, "Video game playing increases food intake in adolescents: a randomized crossover study", The American Journal of Clinical Nutrition, Vol.93, no.6, pp. 1196-1203, 2011, DOI: 10.3945/ajen.110.008680.

[20] Andreyeva T, Kelly IR, Harris JL, "Exposure to food advertising on television: associations with children's fast food and soft drink consumption and obesity", Economics and Human Biology, Vol.9, no.3, pp. 221-233, 2011, DOI: 10.1016/j.ehb.2011.02.004.

[21] Vandelanotte C, Sugiyama T, Gardiner P, Owen N, "Associations of leisure-time internet and computer use with overweight and obesity, physical activity and sedentary behaviors: cross-sectional study", Journal of Medical Internet Research, vol. 11, no. 3, pp. e28, 2009, DOI: $10.2196 /$ jmir.

[22] Lazarou C, Soteriades ES, "Children's physical activity, TV watching and obesity in Cyprus: the CYKIDS study", European Journal of Public Health, vol.20, no.1, pp.70-77, 2010, DOI: 10.1093/eurpub/ckp093.

[23] Yi X, Yin C, Chang M, Xiao Y, "Prevalence and risk factors of obesity among school-aged children in Xi'an, China", European Journal of Pediatrics, Vol.171, no.2, pp.389-394, 2012, DOI: 10.1007/s00431-011-1566-7.

[24] Taheri S, Lin L, Austin D, Young T, Mignot E, "Short sleep duration is associated with reduced leptin, elevated ghrelin, and increased body mass index", PLOS Medicine, vol.1, no.3, pp. e62, 2004, DOI: 10.1371/journal.pmed.001 0062 .

[25] Hitze B, Bosy-Westphal A, Bielfeldt F, Settler U, Plachta-Danielzik S, Pfeuffer M, Schrezenmeir J, Mönig H, Müller MJ, "Determinants and impact of sleep duration in children and adolescents: data of the Kiel Obesity Prevention Study", European Journal of Clinical Nutrition, vol. 63, no. 6, pp. 739-746. 2009, DOI: 10.1038/ejen.2008.41.

[26] Al-Disi D, Al-Daghri N, Khanam L, Al-Othman A, Al-Saif M, Sabico S, Chrousos G, "Subjective sleep 
duration and quality influence diet composition and circulating adipocytokines and ghrelin levels in teen-age girls", Endocrine Journal, vol. 57, no. 10, pp. 915-923, 2010, DOI: 10.1507/endocrj. k10e-145.

[27] Klingenberg L, Chaput JP, Holmback U, Jennum P, Astrup A, Sjodin A, "Sleep restriction is not associated with a positive energy balance in adolescent boys", The American Journal of Clinical Nutrition, vol. 96, no.2, pp.:240-248, 2012, DOI: :10.3945/ajcn.112.038638.

[28] Van den Bulck J, "The effects of media on sleep", Adolescent Medicine: State of the Art Reviews, vol. 21, no.3, pp. 418-429, 2010, vii. PMID: 21302852.

[29] Adam EK, Snell EK, Pendry P, "Sleep timing and quantity in ecological and family context: a nationally representative time-diary study", Journal of Family
Psychology, vol. 21, no.1, pp. 4-19, 2007, DOI: 10.1037/0893-3200.21.1.4.

[30] Dorofaeff TF, Denny S, "Sleep and adolescence. Do New Zealand teenagers get enough?", Journal of Paediatrics and Child Health, vol. 42, no. 9, pp. 515-520. 2006, DOI: 10.1111/j.1440-1754.2006.00914.x.

[31] Carskadon MA, Harvey K, Duke P, Anders TF, Litt IF, Dement WC, "Pubertal changes in daytime sleepiness", Sleep. vol. 2, no.4, pp. 453-460, 1980, DOI: 10.1093/sleep/2.4.453.

[32] Navya Pratyusha M, Rajyalakshmi K, Apparao B V, Charankumar G, "Impact of Sleep on Usage of the Smart Phone at the Bedtime- A Case Study," Mathematics and Statistics, Vol. 9, No. 1, pp. 31-35, 2021. DOI: 10.13189/ms.2021.090105. 